\title{
THE INFLUENCE OF INDENTER ROTATION ANGLE ON THE QUALITY OF VICKER TESTER CALIBRATION
}

\author{
JOZEF PETRÍK
}

\section{INTRODUCTION}

Like in any test of mechanical properties, there is obvious requirement for reliability of measurement results, which is unthinkable without sufficient quality of measurement process. Metrological confirmation shall be designed and implemented to ensure that the metrological characteristics of the measuring equipment satisfy the metrological requirements for the measurement process. Metrological confirmation comprises measuring equipment calibration and measuring equipment verification (ISO 10 012:2003). A calibration system is a set of operations that establish, under specified conditions, the relationship between a measuring device and a traceable CRM (certified reference material, standard) of known reference value and uncertainty. Calibration may also include steps to detect, correlate, report, or eliminate by adjustment any discrepancy in accuracy of the measuring device being compared (MSA).

A perfect measurement would obtain the true value of a quantity, which is the value consistent with the definition of a given quantity. True values are, by nature, indeterminable because a perfect measurement cannot be performed. In fact, it is impossible to fully describe the measured value without an infinite amount of information. In other words, the final corrected result of a measurement is, at best, an estimate of the true value of the quantity that someone intended to measure. The measurement uncertainty is a parameter that characterizes the dispersion of the values that could reasonably be attributed to the measured value. A calibration laboratory, or a testing laboratory performing its own calibrations, shall have and shall apply a procedure to estimate the uncertainty of measurement for all calibrations and types of calibrations. Testing laboratories shall have and shall apply procedures for estimating uncertainty of measurement or calibration. When estimating the uncertainty of measurement, all uncertainty components, which are of importance in the given situation shall be taken into account using appropriate methods of analysis (ISO/IEC 17 025:2005).

For indirect calibration of Vickers hardness tester against certified reference material (CRM) according to the respective standard there is not usually problem to keep the requirements for repeatability $r_{\text {rel }}$ and maximum relative error $E_{\text {rel }}$. The problem is the maximum permissible deviation of the tester including its measurement uncertainty (equivalent to relative expanded uncertainty of calibration $\mathrm{U}_{\text {rel }}$ ) as a rule. The measuring device is nonconforming and shall be 
removed from service if the value of $U_{\text {rel }}$ higher than the value permitted by the standard (ISO 10 012:2003).

The standard sources of uncertainty regarding to indenter of Vickers tester are geometrical deviations of indenter, deformation of the indenter under test force, surface roughness of indenter, mechanical damage of the indenter, form deviations of indenter, plane angle, tip radius, length of line of junction (EA10/16, 2004). Another source of uncertainty can be position of indenter in bearing - its rotation angle along to vertical axis of tester. The position of indenter is not marked, for example by bayonet plug. This fact permit its fixation with the fastening screw in random angle (revolving) within the range $0^{\circ}-360^{\circ}$.

The objective of research is the study of indenter rotation angle influence on the results of Vickers hardness tester calibration.

\section{METHODOLOGY}

Calibrated tester HPO 250 (VEB Werkstoffprüfmaschinen „Fritz Heckert“, East Germany, 1982) meets the requirements of standard (STN EN ISO 6507-2:2005) regarding to the result of direct calibration $(\mathrm{V} / 10)$.

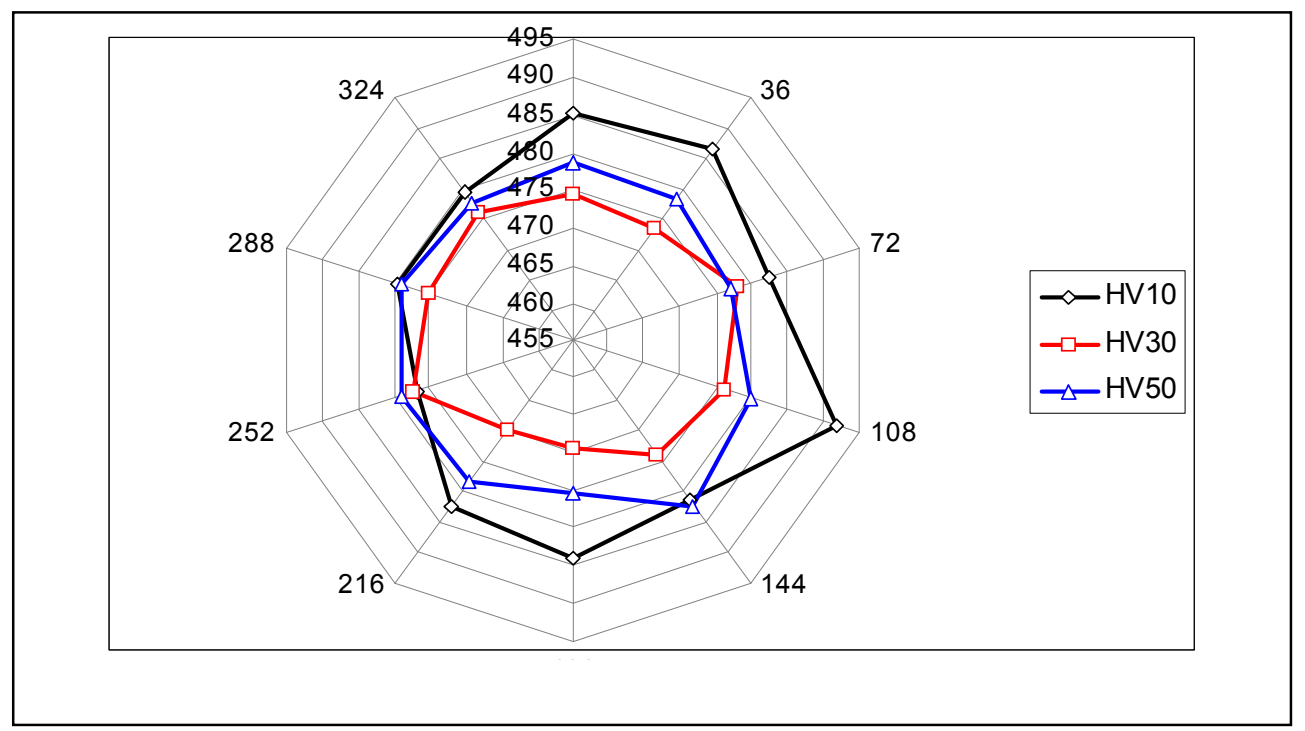

Figure 1 - The influence of the rotation of indenter in the hardness

The certified reference material (CRM) in form of hardness reference block with specified hardness $\mathrm{H}_{\mathrm{c}}=472.4 \mathrm{HV} 10$ and expanded uncertainty $\mathrm{U}_{\mathrm{CRM}}= \pm 9.448$ HV10 (coverage factor $\mathrm{k}=2$ ) was used as a standard for indirect calibration according to standard (STN EN ISO 6507-2:2005). The test forces/loads 98.07 N (HV10), 294.2 N (HV30) and 490.3 (HV50) were applied. 


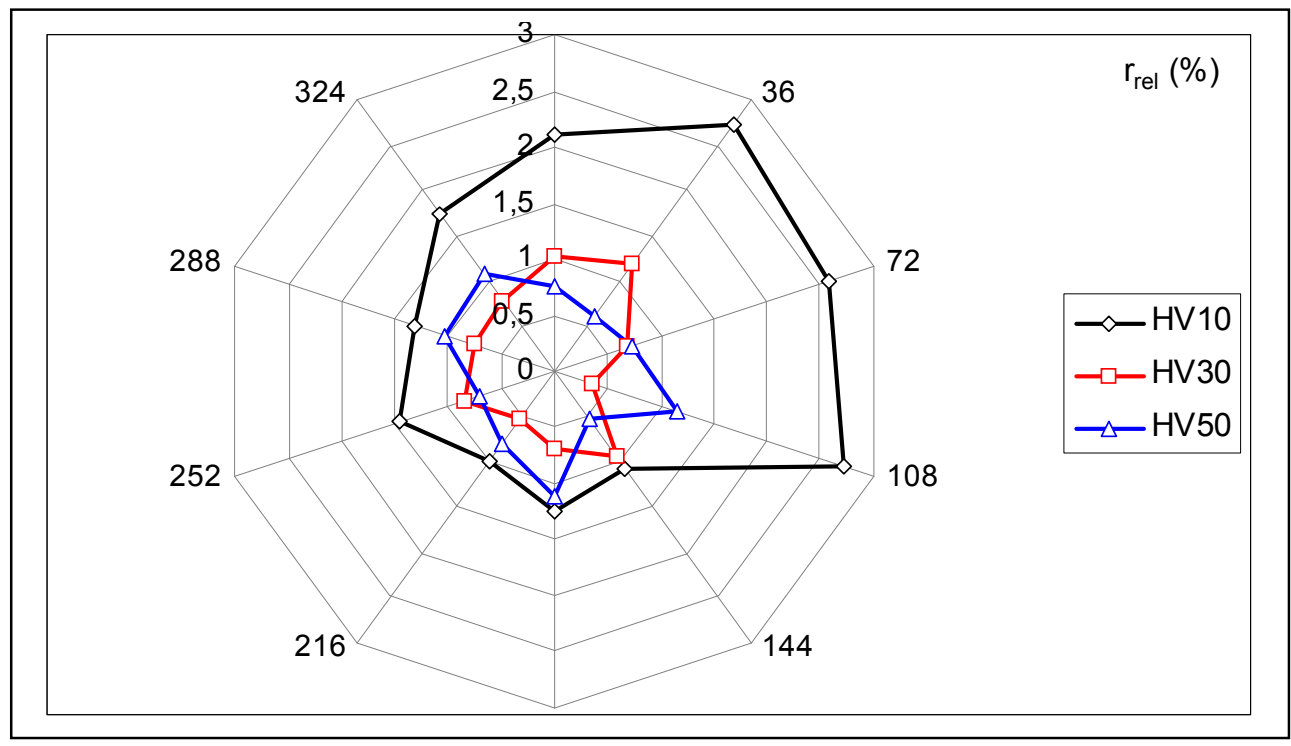

Figure 2 - The influence of the rotation of indenter on the repeatibility $r_{\text {rel }}$

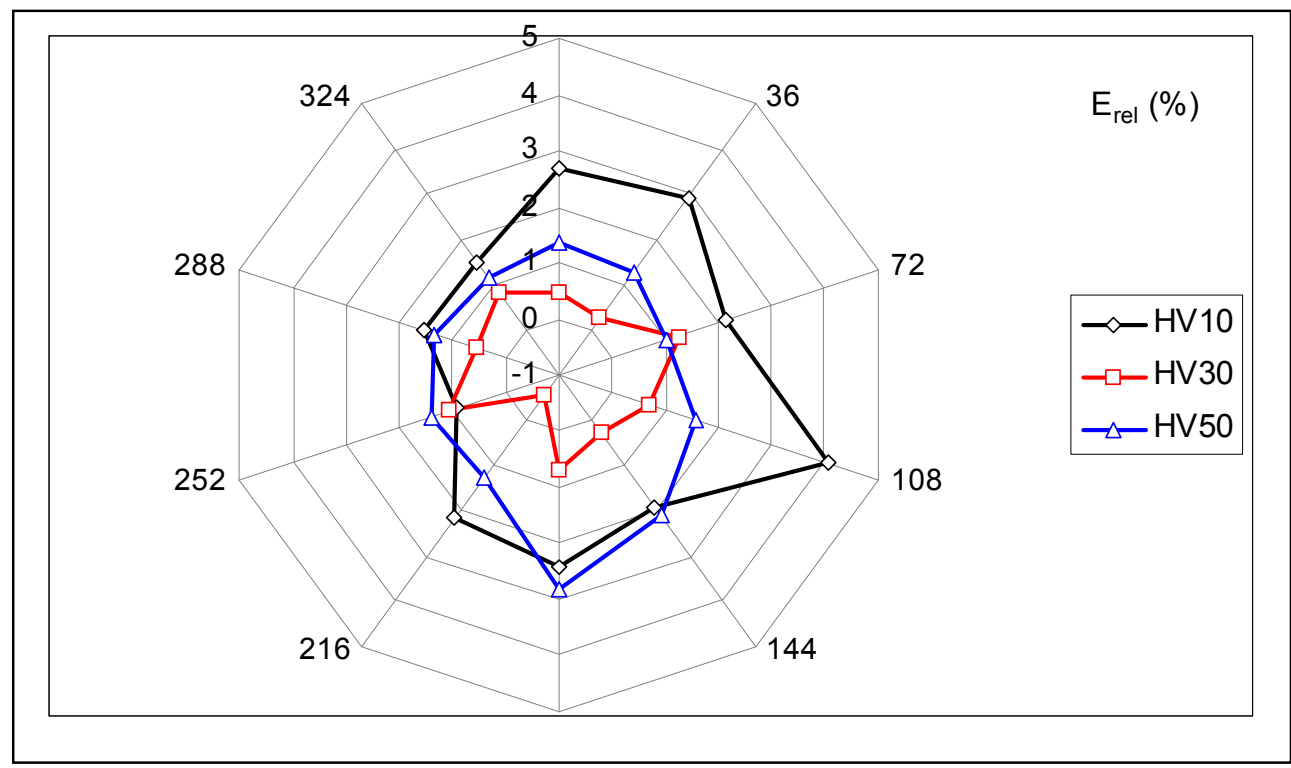

Figure 3 - The influence of the rotation of indenter on the maximal error Erel

To determine the influence of the indenter rotation angle on the results of calibration, it was step by step turned by $36^{\circ}\left(0^{\circ}-324^{\circ}\right)$ after individual calibration. The ambient temperature was $18.8-21.2^{\circ} \mathrm{C}$. Five indentations were applied along the radius (from centre to rim) of CRM in equidistant intervals 
with it slewing (about $30^{\circ}$ ) of the CRM after each indentation. The force application time was 15 seconds.

Table 1 - The results of indirect calibration values of standard deviations $s_{H}$ (in $H V)$ for individual indenter rotation angles and test forces

\begin{tabular}{|l|c|c|c|c|c|c|c|c|c|c|}
\hline $\begin{array}{l}\text { Angle of } \\
\text { indenter }\end{array}$ & $0^{\circ}$ & $36^{\circ}$ & $72^{\circ}$ & $108^{\circ}$ & $144^{\circ}$ & $180^{\circ}$ & $216^{\circ}$ & $252^{\circ}$ & $288^{\circ}$ & $324^{\circ}$ \\
\hline HV10 & 8.13 & 9.43 & 9.37 & 10.03 & 4.69 & 5.34 & 4.70 & 5.11 & 5.23 & 9.52 \\
\hline HV30 & 3.45 & 4.42 & 2.58 & 1.35 & 3.20 & 2.64 & 2.34 & 3.06 & 2.75 & 3.14 \\
\hline HV50 & 2.95 & 2.26 & 2.94 & 4.68 & 2.07 & 4.21 & 3.46 & 2.57 & 4.00 & 4.06 \\
\hline
\end{tabular}

The average values of hardness are on fig. 1 and values of standard deviations $\mathrm{s}_{\mathrm{H}}$ for individual angles of indenter and test forces are in tab. 1.

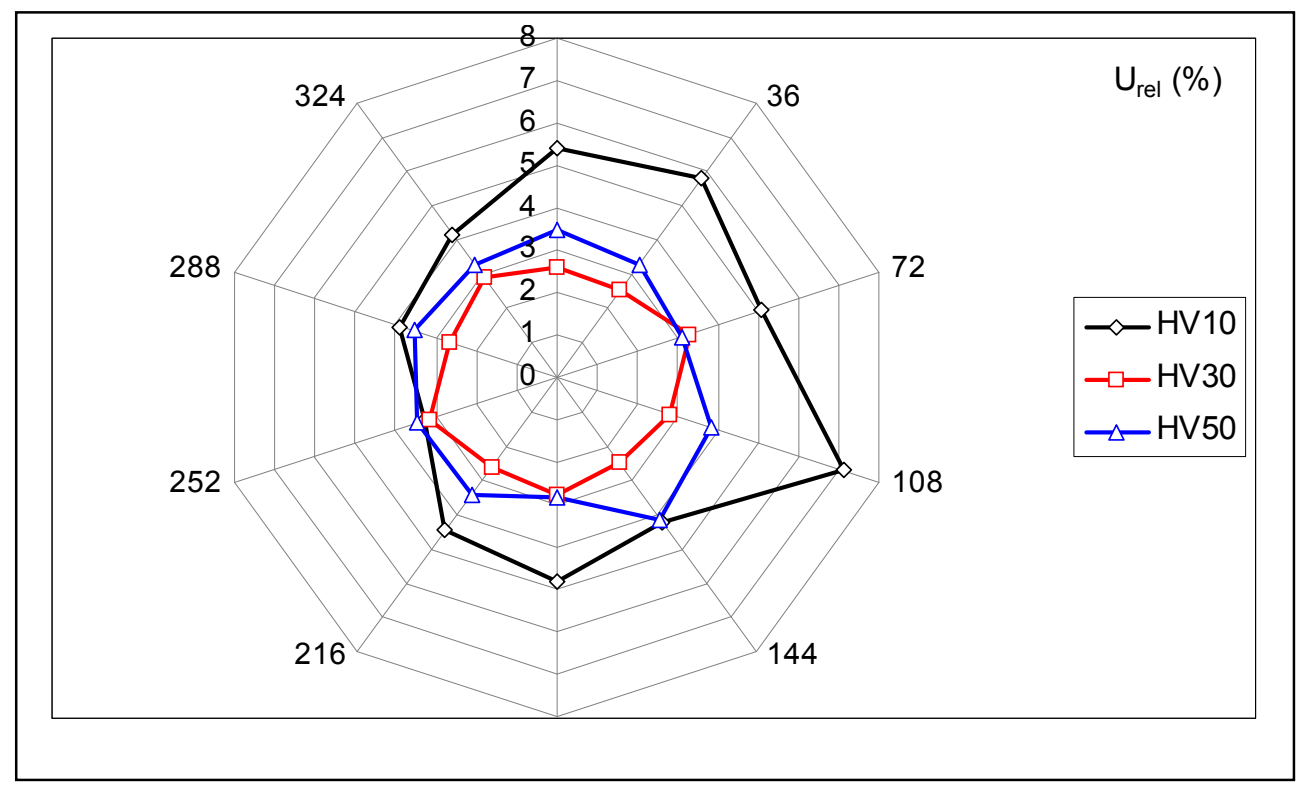

Figure 4 - The influence of the rotation of indenter on the uncertainty Urel

The first step of analysis is to estimate whether the discrimination (effective resolution) $\mathrm{d}^{*}$ - the value in $\mathrm{HV}$ of the smallest scale division (graduation) of measurement equipment is sufficient. A general rule of thumb is that the discrimination ought to be at least one - tenth the process variation (standard deviation $\mathrm{s}_{\mathrm{H}}$ in tab. 1). If we compare the values in tables 1 and 2 , used tester more or less meets this condition. 
Table 2 - The average values of discrimination (effective resolution) $d^{*}$

\begin{tabular}{|l|l|l|l|}
\hline & HV10 & HV30 & HV50 \\
\hline$d^{*}[$ HV $]$ & 0.497 & 0.277 & 0.220 \\
\hline
\end{tabular}

Grubbs' test (significance level $\alpha=0.05$ ) detected no outlier. The doubts concerning the normality of distribution will be finally dissolved if the procedure for the tests of the concordance between the method error distribution and the theoretical distribution is applied (Adamczak et al, 2011). The normality was estimated by Freeware Process Capability Calculator (3.0.0) software by Anderson - Darling test (significance level $\alpha=0.05$ ). The files of HV10 ( $\mathrm{p}=$ $0.22681)$ and HV50 ( $p=0.82597)$ have normal distribution $(\mathrm{p} \geq 0.07)$, but the normality of file HV30 was not confirmed $(p=0.04178)$. The standard methods of MSA assume normal probability distribution. If normality of the file is not confirmed, the measurement system error is overestimated.

\subsection{Calculation of repeatibility, maximal error and uncertainty}

The repeatability of tester $\quad \mathrm{r}_{\text {rel }}=100 \times \frac{d_{5}-d_{1}}{\bar{d}} \%$

$\bar{d}$ is the mean, $\mathrm{d}_{5}$ is the maximum and $\mathrm{d}_{1}$ is minimum value of indentations diagonals.

The error at specific conditions of calibration $\quad E=\bar{H}-H_{c}$

$\bar{H}$ is the average hardness of CRM

Relative maximum error $\quad \mathrm{E}_{\mathrm{rel}}=100 \times \frac{\bar{H}-H_{c}}{H_{c}} \%$

The uncertainty of indirect calibration:

$$
\mathrm{u}_{\mathrm{HTM}}=\sqrt{u_{C R M}^{2}+u_{C R M-D}^{2}+u_{H}^{2}+u_{m s}^{2}}
$$

The standard uncertainty of used CRM $\mathrm{u}_{\mathrm{CRM}}=4.724$ HV10. The uncertainty resulted drift of CRM $\mathrm{u}_{\text {CRM-D }}$ was ignored (used CRM was calibrated only once)

Standard uncertainty of hardness tester $\mathrm{u}_{\mathrm{H}}=\frac{t \times s_{H}}{\sqrt{n}}$

$\mathrm{S}_{\mathrm{H}}$ is standard deviation (table 1), Student's factor $\mathrm{t}=1.15$ for $\mathrm{n}=5$ (number of trials) and significance level $\alpha=0.317$.

Another source of uncertainty is measuring device. 


$$
\mathrm{u}_{\mathrm{ms}}=\frac{2 \bar{H}}{d} \frac{\delta_{m s}}{2 \sqrt{3}}
$$

$\delta_{m s}=0.001 \mathrm{~mm}$ is the sensitivity of indentations measuring device at magnification $70 \times$.

$$
\mathrm{d}=\sqrt{0.1891 \times \frac{F}{\bar{H}}}
$$

$\mathrm{F}=$ test force $(\mathrm{N})$

The error of calibration

$$
\bar{b}=\bar{H}-H_{c}=E
$$

The maximum error of the tester including the measurement expanded uncertainty $\mathrm{U}_{\mathrm{HTM}}$ (coverage factor $\mathrm{k}=2$ ):

$$
\begin{gathered}
\mathrm{U}_{\mathrm{HTM}}=\mathrm{k} \times \mathrm{u}_{\mathrm{HTM}} \\
\Delta H_{H T M \max }=U_{H T M}+|\bar{b}|
\end{gathered}
$$

Relative maximum error of the tester (relative expanded uncertainty of calibration):

$$
\mathrm{U}_{\text {rel }} \frac{\Delta H_{H T M \max }}{\bar{H}} \times 100 \%
$$

The values of $r_{\text {rel }}, E_{\text {rel }}, U_{\text {rel }}$ are on fig. 2, 3 and 4. The maximum permissible values are $r_{\text {rel }} \leq 2 \%$ for all used test forces, $E_{\text {rel }}$ and $U_{\text {rel }} \leq \pm 3 \%$ for HV10 and $\leq$ $\pm 2 \%$ for HV30 and HV50 accorging to standard (STN EN ISO 6507-2:2005). The tester do not meet the requirements of standard for all calibrations with respect to $U_{\text {rel }}$. It is possible that high value of uncertainty of calibration is a result of low capability (high value of \%GRR) of equipment (Tobolsky, 2003).

\subsection{Measurement systems analysis (MSA)}

The capability of calibration process can be evaluated by analysis of measurement system (MSA - Measurement Systems Analysis), which helps to conform with ISO/TS 16 949:2002 requirements. If the analyzed measurement system is capable, it is likely that the measurement process, taking place in it is capable as well.

The GRR, one of MSA methods is an experimental and mathematical method of determining measurement repeatability and reproducibility. The computation of capability indices was carried out according to (MSA, 2010). The software Palstat CAQ with significance level $\alpha=0.01$ and confidence significance level $\alpha=0.05(5.15 \sigma)$ was used for capability calculation.

The measurement system ought to be under statistical control before capability is assessed. The process is under the control, if all ranges in the the range (R) 
control chart are between control limits. This condition was not met for HV10. The number of distinct categories ("ndc", based on Wheeler's discrimination ratio) is connected by the question of the resolution of measurement equipment. The "ndc" is greater than or equal to 5 for capable processes. The calculated "ndc" value 0.432 is unsatisfactory.

The area within the control limits of the X-bar control chart represents measurement sensitivity (,noise"). Since measurements used in the study represent the process variation, approximately one half or more of the averages should fall outside the control limits. Only $16.7 \%$ of measurements were outside control limits. The measurement system lacks adequate effective resolution or the sample does not represent the expected process variation.

The index $\% \mathrm{EV}=70.1 \%$ represents the cumulative influence of measurement equipmentand environmental conditions on the variability. It is a function of average range of trials of all test forces.

The index $\% \mathrm{PV}=20.3 \%$ is a function of range of average hardness of calibration at individual indenter rotation angle.

The index $\% \mathrm{AV}=65.0 \%$ represents the influence of used test method (test force) on variability. It is a function of average values from individual test forces.

Analyzed process is not capable, as the value of index \%GRR $=95.6 \%$ (above $10 \%$ limit). Low capability is typical for hardness and micro-harness measurement (Petrík, Palfy, 2009).

The influence of the rotation angle on capability, expressed by index $\% \mathrm{PV}$ is far less than the influence of the test force, expressed by index \%AV.

\subsection{Analysis of variance (ANOVA)}

According to single factor ANOVA the influence indenter rotation angle of on the hardness is not statistically significant for $\operatorname{HV} 10(\mathrm{p}=0.136496)$ and for HV50 $(p=0.25264)$, but it is statistically significant for HV30 $(\mathrm{p}=0.00242)$.

Table 3 - The influence of test force and rotation angle of indenter on $r_{r e l}, E_{\text {rel }}$, $U_{\text {rel }}-p$ values

\begin{tabular}{|l|l|l|l|}
\hline & $\mathrm{r}_{\text {rel }}(\%)$ & $\mathrm{E}_{\text {rel }}(\%)$ & $\mathrm{U}_{\text {rel }}(\%)$ \\
\hline test force & 0.000109 & 0.000102 & $1.55 .10^{-5}$ \\
\hline angle of indenter & 0.555716 & 0.500989 & 0.610559 \\
\hline
\end{tabular}

According to two factor ANOVA with replication the influences of test force ( $\mathrm{p}$ $=8.37 .10^{-13}$ ) has statistically significant effect on hardness, but the rotation angle of indenter $(\mathrm{p}=0.094791)$ has not. 
According to two factor ANOVA without replication the test force (but not angle of indenter) has statistically significant effect on $r_{\text {rel }}, E_{\text {rel }}$ and $U_{\text {rel }}$ (tab. 3).

\subsection{Z-score}

Z-score method, routinely applied in interlaboratory comparison tests was used for validation of above mentioned results. The value for individual calibration is:

$$
z_{i}=\frac{x_{i}-\bar{x}}{s}
$$

$x_{i}$ is the average hardness of one calibration, $\bar{x}$ specified hardness of CRM $\mathrm{H}_{\mathrm{c}}=$ $472.4 \mathrm{HV}$ and , $\mathrm{s}$ “ is standard uncertainty $\mathrm{u}_{\mathrm{CRM}}=4.724 \mathrm{HV}$. The results $\left|z_{i}\right| \leq 2$ are satisfactory and $\left|z_{i}\right| \geq 3$ are unsatisfactory (Palenčár et al, 2001). One unsatisfactory and five conditionally satisfactory results were obtained (only for HV10). All other results are satisfactory (fig. 5).

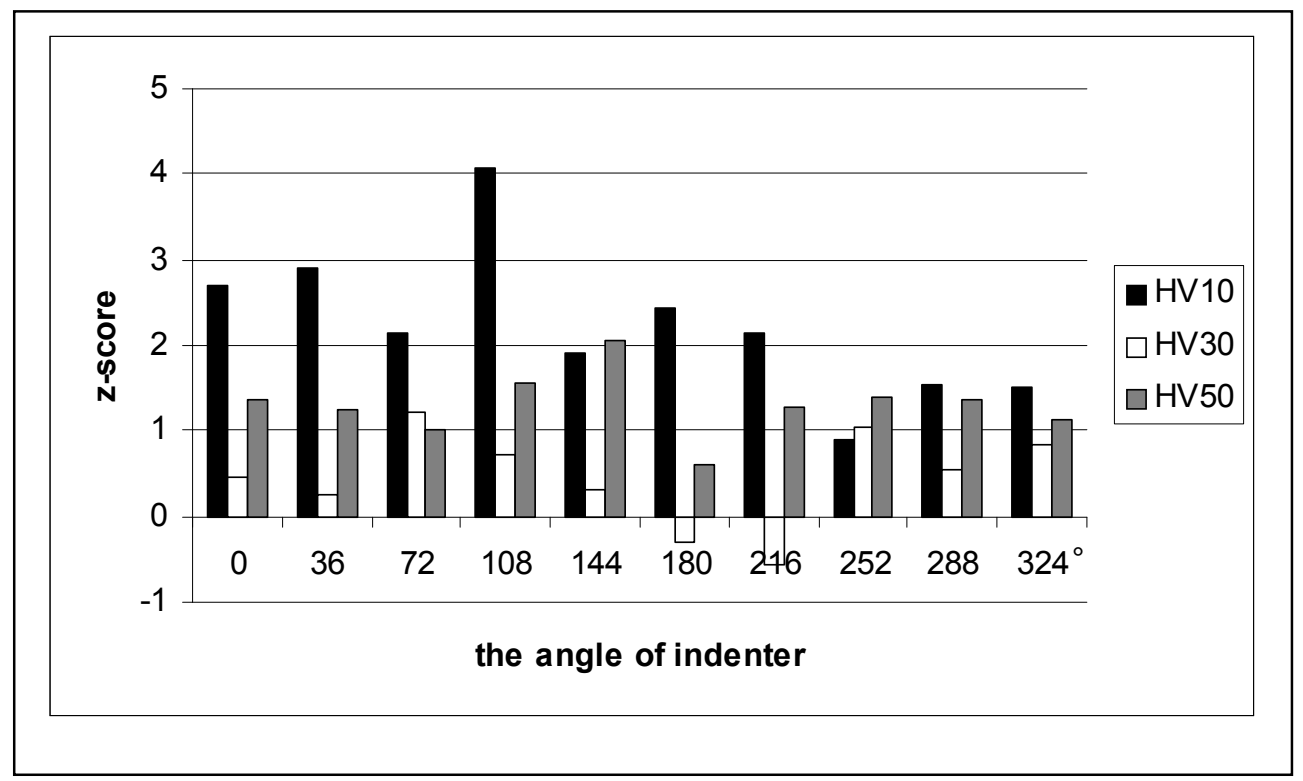

Figure 5-Z-score

\subsection{Discussion}

The influence of the test forces on the differences between the values of hardness is minimal at indenter angles between $252^{\circ}$ and $324^{\circ}$. The minimal values of $\mathrm{E}_{\mathrm{rel}}$ and $\mathrm{U}_{\text {rel }}$ with minimal influence of test force are at that same interval of angles. The minimal values of $r_{\text {rel }}$ are between $180^{\circ}$ and $252^{\circ}$. The best results are at angle $252^{\circ}$. The most significant differences between diagonals, and the high values of hardness, $\mathrm{r}_{\text {rel }}, \mathrm{E}_{\text {rel }}$ and $\mathrm{U}_{\text {rel }}$ were obtained at angle $108^{\circ}$. The unsatisfactory results at angle $108^{\circ}$, especially at HV10 confirms also z-score. 


\section{CONCLUSION}

1) The influence of the rotation angle of indenter on the hardness can be statistically significant in dependence of test force.

2) The angle of indenter affects $r_{\text {rel }}, E_{\text {rel }}$ and $U_{\text {rel }}$ more significantly at HV10 than at HV30 and HV50.

3) The best results of $r_{\text {rel }}, E_{\text {rel }}, U_{\text {rel }}$ with negligible influence of test force were observed at angle $252^{\circ}$.

4) The significance of the angle of indenter on the hardness and observed parameters of calibration no such as it of test force, but not negligible.

Further research will be focused on preparation of factual and generalized knowledge about creative laboratory teaching at Higher Education Institution technical faculties especially in the field of Production Quality, especially: design, realization and work methods in Creative Laboratory Tuition at Technical Faculties (CRELABTE).

\section{AFFILIATION}

Incorporated in the paper are interim results of the Slovak Republic Ministry of Education Project KEGA 009-4/2011: Creative Laboratory Tuition at Technical Faculties (CRELABTE).

\section{REFERENCES}

ISO 10 012:2003 Measurement management systems - Requirements for measurement processes and measuring equipment.

ISO/IEC 17 025:2005 General requirements for the competence of testing and calibration laboratories.

EA-10/16 (2004) EA Guidelines on the Estimation of Uncertainty in Hardness Measurements. Annex Guideline to the evaluation of the uncertainty of the Brinell and the Vickers measuring Method.

Adamczak, S. et al. (2011) "Statistical validation of the method for measuring radius variations on the machine tool". Metrology and Measurement Systems, Vol. 18, No. 1, pp. 35-47.

STN EN ISO 6507-2:2005 Metallic materials. Vickers hardness test. Part 2: Verification and calibration of testing machines.

Measurement system s analysis (MSA). Reference manual. Fourth edition. 2010. 
International Vocabulary of Basic and General Terms in Metrology VIM. [online]. [cited 14 March 2008]. Available from:

$<$ http://www.ntmdt.ru/download/vim.pdf $>$.

Tobolski, E. (2003) "Uncertainty in Hardness testing", Advanced materials \& processes, Vol. 161 No. 5, pp. 25-27.

Petrík, J. - Palfy, P. (2009) "The sources of uncertainty in Vickers hardness tester calibration", Transaction of the Universities of Košice. Vol. 19, No.2, pp. 58-70, ISSN 1335-2334.

Palenčár, R. et al. (2001) Štatistické metódy v metrologických a skúšobných laboratóriách. Bratislava. Grafické štúdio Ing. Peter Juriga, ISBN 80-968449-3-8

\section{ABOUT THE AUTHOR}

Assoc. prof. Jozef Petrík, PhD. is associated professor in Department of Integrated Management. He deals with metrology, the first of all quality of metallurgical values measurement. Technical University of Košice, Faculty of Metallurgy, Letná 9, 042 00, Košice, Slovakia, tel.: +421 55602 2872, e-mail: jozef.petrik@tuke.sk. 